\section{Phrynoderma: a cutaneous sign of an inadequate diet}

A 28-year-old man was referred to our dermatology clinic with a 6month history of diffuse and slightly pruritic papules. These hyperkeratotic, follicular, cutaneous lesions were mainly located on the patient's trunk (Figure I), shoulders and extensor surfaces of his arms and legs. Two years before presentation, the patient weighed $139 \mathrm{~kg}$ (body mass index $40.2 \mathrm{~kg} / \mathrm{m}^{2}$ ), and he had received treatment for obesity, which included a biliopancreatic diversion and a restricted diet $(<1000 \mathrm{kcal} / \mathrm{d})$. At the time of presentation, the patient weighed $102 \mathrm{~kg}$ and his body mass index was $29.5 \mathrm{~kg} / \mathrm{m}^{2}$. He had taken no medications for obesity management and experienced mild, nonspecific muscle aches and weakness during his 2-year weight loss.

A second man, aged 23 years, was referred to our clinic with an 8-month history of intensely pruritic lesions on his trunk and on the extensor surfaces of his extremities. About 4 months before the onset of the lesions, the patient had started a self-prescribed diet to lose weight, which included avoiding leafy green vegetables, fresh fruit, oils and eggs. In the year prior to presenta- tion, his weight had decreased from I22 $\mathrm{kg}$ (body mass index $36.8 \mathrm{~kg} / \mathrm{m}^{2}$ ) to $95 \mathrm{~kg}$ (body mass index $28.7 \mathrm{~kg} / \mathrm{m}^{2}$ ). Clinical examination revealed multiple keratotic, spiny papules and diffuse cutaneous xerosis (Figure 2).

Both patients were otherwise healthy, without mucosal, ocular or systemic abnormalities. Results of routine laboratory investigations were all within the normal range; however, both men had deficiencies in several vitamins and minerals. The first patient's vitamin A level was 0.42 (normal 0.70-2.09) $\mu \mathrm{mol} / \mathrm{L}$, his vitamin E level was Io (normal I2-42) $\mu \mathrm{mol} / \mathrm{L}$ and his zinc level was 8.4 (normal I2.2-24.5) $\mu \mathrm{mol} / \mathrm{L}$. The second patient also had a low level of vitamin A $(0.52 \mu \mathrm{mol} / \mathrm{L})$ and vitamin $\mathrm{E}(9 \mu \mathrm{mol} / \mathrm{L})$, as well as a deficiency of essential fatty acids (ratio of trienoic acid to tetraenoic acid 0.5 [normal < 0.4]). Histologic examination of skin biopsies from both patients revealed focal hyperparakeratosis, irregular acanthosis and dilated hair follicles filled with keratin plugs (Figure 3).

The clinical differential diagnoses in both cases included phrynoderma, prurigo nodularis, follicular lichen planus, Kyrle's disease and Besnier's prurigo. Both patients received a diagnosis of phrynoderma caused by inappropriate nutrition and were given topical keratolytic ointments (urea 10\%$30 \%$ ) and an equilibrated calorie regimen (I500-2000 kcal/d) with nutritional supplements. These supplements included vitamin A (50 000 U/d for I month, then $5000 \mathrm{U} / \mathrm{d}$ for 2 months), vitamin E (alpha-tocopherol $300 \mathrm{mg} / \mathrm{d}$ ) and vitamin $\mathrm{B}$-complex (thiamine 3 $\mathrm{mg} / \mathrm{d}$, nicotinamide $30 \mathrm{mg} / \mathrm{d}$, riboflavin I $\mathrm{mg} / \mathrm{d}$, calcium pantothenate $\mathrm{I} \mathrm{mg} / \mathrm{d}$, pyridoxine hydrochloride $0.5 \mathrm{mg} / \mathrm{d}$, cyanocobalamin $5 \mathrm{mg} / \mathrm{d}$ ), as well as vitamin C $(500 \mathrm{mg} / \mathrm{d})$ and essential fatty acids (safflower oil $5 \mathrm{~mL} / \mathrm{d}$ ). Both patients experienced a complete regression of the follicular papules within 3-6 months.

Phrynoderma is a form of follicular hyperkeratosis that is associated with nutritional deficiencies. It is endemic to poor populations but is rare in developed countries. ${ }^{1}$ The term "phrynoderma" was coined by Nicholls in 1933 to describe the "toad-like" appearance of the skin of undernourished labourers. ${ }^{1}$ This form of dermatosis can be caused by isolated deficiencies of vitamins A, B complex, C and E. ${ }^{1,2}$ Adjunc-

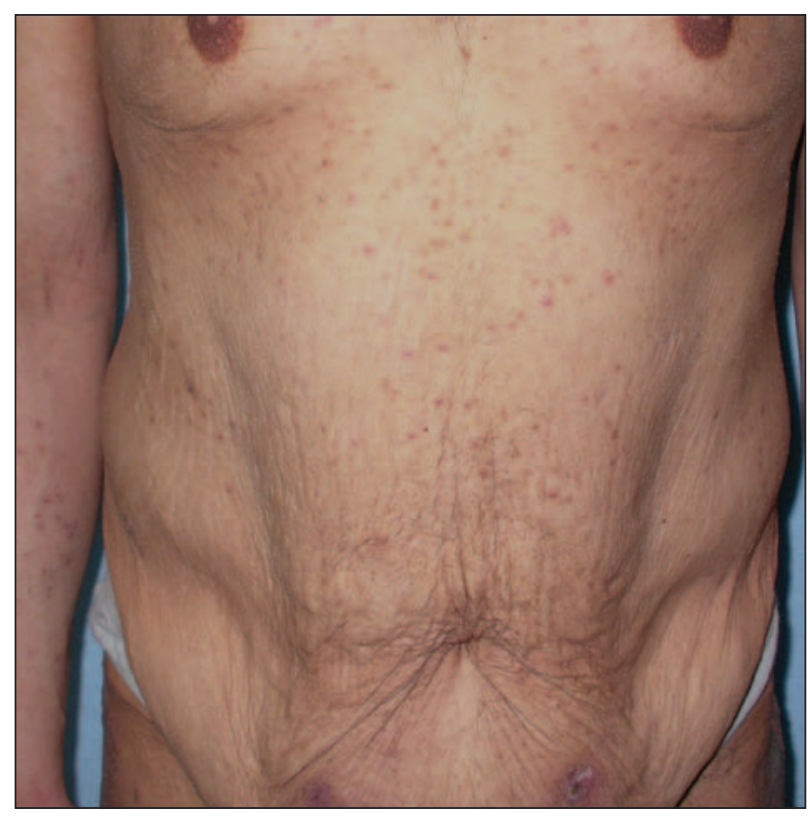

Figure 1: Multiple keratotic follicular papules on the trunk of patient 1.

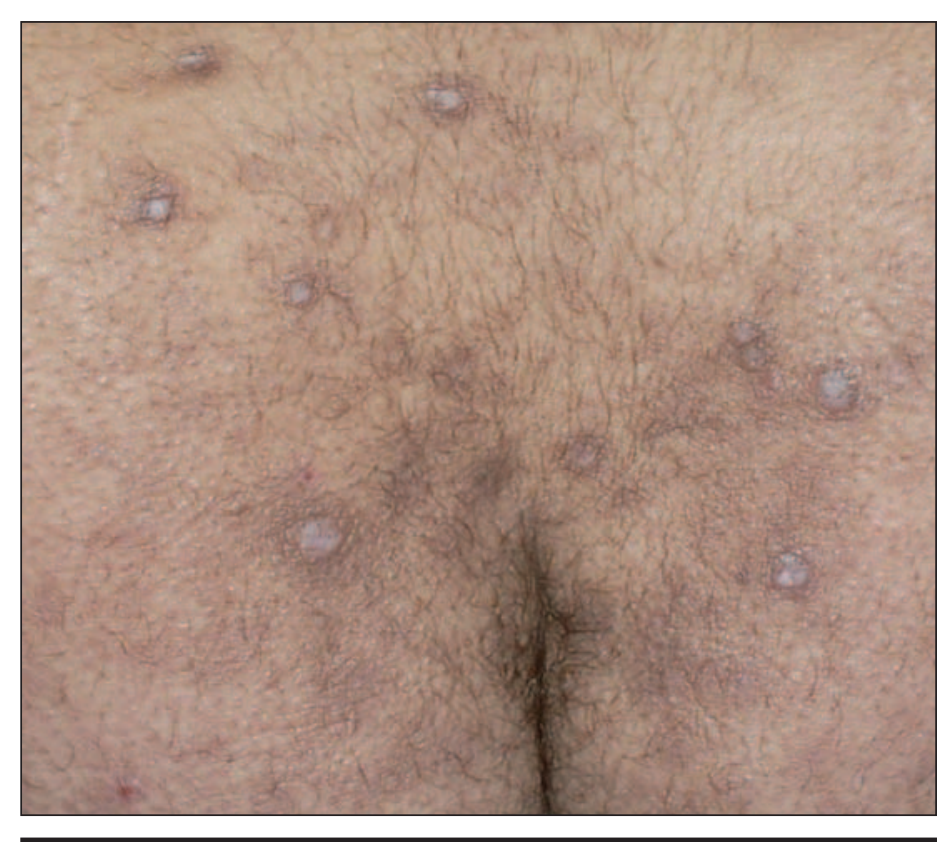

Figure 2: Cup-shaped spiny papules with a thorny, scaly surface and follicular hyperkeratosis on the sacral region of patient 2 . 
tive symptoms, such as cheilitis, glossitis, blepharitis, night blindness, diarrhea, muscle weakness and neuritis,

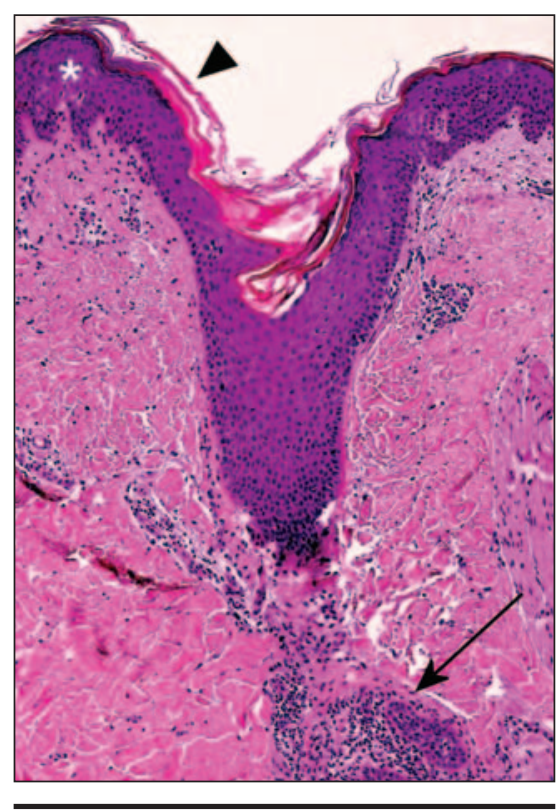

Figure 3: Biopsy specimen showing mild epidermal acanthosis (asterisk) with hyperkeratosis (arrowhead), dilated hair follicles with keratin plugs and sparse dermal inflammatory infiltrates (arrow) (hematoxylin-eosin stain, original magnification $\times 100$ ). may develop when hypovitaminosis A is predominant relative to other vitamin deficiencies. ${ }^{1,2}$ These systemic abnormalities were absent in our patients, which is consistent with the current hypothesis that phyrnoderma is caused by a combination of nutritional deficiencies. ${ }^{2}$

In developed countries, phrynoderma most often occurs as a result of malabsorption due to surgical or medical causes, such as small-bowel bypass surgery, colectomy and pancreatic insufficiency. ${ }^{3}$ However, as demonstrated by our second patient, phrynoderma can also develop if a patient follows a calorie-restricted diet $(<700 \mathrm{kcal} / \mathrm{d}$ ) and strictly avoids vegetables, fruit and fats. Health care providers should be attentive to the nutritional needs of patients at risk for malnutrition, including those who have been prescribed a strict weight-loss regimen and those who may be in a malabsorptive state, such as patients who have undergone bariatric surgery. For these patients, health care providers should recommend diets, or at least supplements, that are rich in vitamins $\mathrm{A}, \mathrm{B}, \mathrm{C}$ and $\mathrm{E}$, including foods such as yellow vegetables, green leafy vegetables, carrots, whole-milk derivatives, eggs, fish and oils (e.g., fish-liver oil, soybean oil, safflower oil, sunflower oil, corn oil, palm oil, cottonseed oil), as well as unprocessed cereal grains and nuts. ${ }^{1-3}$ Many mild cases of phrynoderma may be overlooked, but if detected early, the underlying nutritional imbalances may be correctable.

\section{Alessandro Di Stefani MD \\ Department of Dermatology \\ Augusto Orlandi MD \\ Department of Anatomic Pathology \\ Sergio Chimenti MD \\ Luca Bianchi MD \\ Department of Dermatology \\ University of Rome \\ Rome, Italy}

This article has been peer reviewed.

Competing interests: None delared.

\section{REFERENCES}

I. Nakjang Y, Yuttanavivat T. Phrynoderma: a review of I05 cases. J Dermatol I988;15:53I-4.

2. Bleasel NR, Stapleton KM, Lee MS, et al. Vitamin A deficiency phrynoderma: due to malabsorption and inadequate diet. J Am Acad Dermatol 1999;4I: 322-4.

3. Barr DJ, Riley RJ, Greco DJ. Bypass phrynoderma. Vitamin A deficiency associated with bowel-bypass surgery. Arch Dermatol I984;120:919-2I.

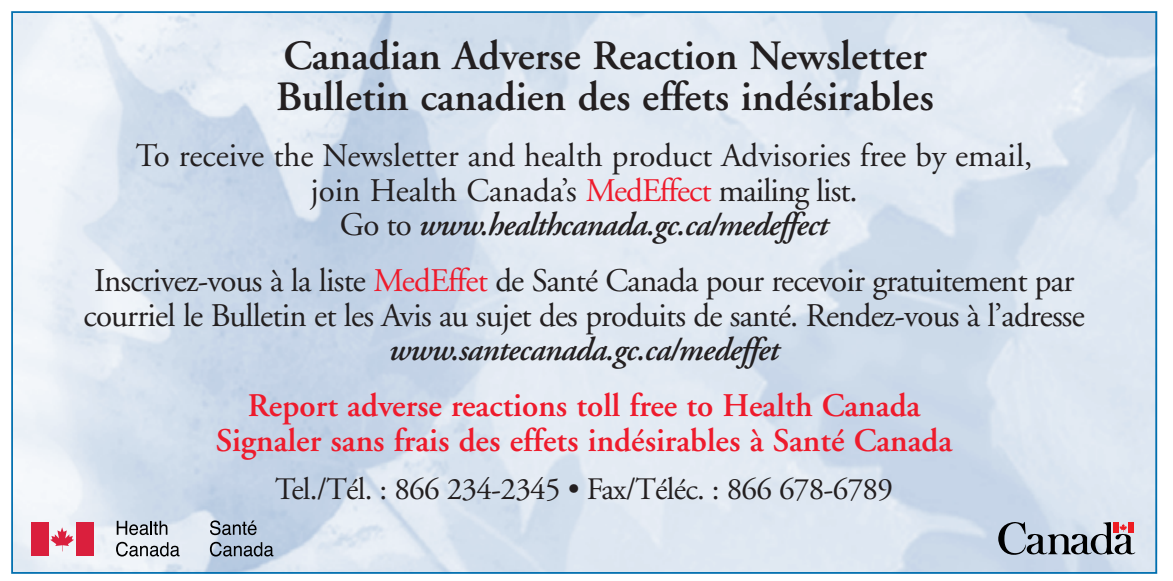

